\title{
First Degree Burns after 1-year of Post Total Knee Replacement: Case Report
}

\author{
Dr S. Muhammad Waqar Saadat MBBS, MRCS, MCH, Mr Sandeep Munshi fRCS, \\ Mr Nadeem Baqai FRcs
}

\section{ABSTRACT}

Introduction: There are reported thermal injuries after prolonged use of laptops in the literature. Now for the first time, we report on a case, in which thermal injuries secondary to laptop over the scar of total knee arthroplasty.

Case Report: We report a case of a 69-year-old lady with a background history of left total knee replacement, who sustained a first degree thermal burn over the scar and lateral aspect of the thigh of the replaced knee after prolonged use of her laptop. To date this is the only case where a laptop burn happened to a patient after having total knee replacement.

Conclusion: This case report highlights the management of such cases and can be used to educate other arthroplasty surgeons how to emphasise to patients about this possible risk associated with prolonged use of laptops in their consultation and consent.

Keywords: First degree burns, laptop, total knee replacement.

\section{INTRODUCTION}

Globally since 2008, sales of laptops or portable computers have surpassed desktop computer sales. ${ }^{6}$ Using laptops is a very uncommon cause of thermal injuries (burns). ${ }^{1}$ The central processing unit (CPU), hard drive, graphics processing unit, ventilation fan, internal CD/DVD and battery are the main components in laptops that generate heat. ${ }^{5}$ Thigh, knee and perineum are most commonly affected as laptops are placed over these parts of the body when in use. Prolonged contact of hot surfaces at the base of the computer with the user's lap can result in burns. ${ }^{2}$ There are multiple risk factors such as lack of protective cover, i.e., clothing, and causes of impaired or altered sensation due to nerve injury, neuropathy secondary to diabetes, quadriplegia/paraplegia or post-surgery loss of sensation in the skin.

\section{CASE REPORT}

No case has been reported of thermal injuries secondary to laptop over the scar of total knee arthroplasty (TKA). We present a case of a 69-year-old lady who attended the arthroplasty follow-up clinic. She had undergone left total knee replacement one year ago and made uneventful recovery. On examination she was noticed to have discoloration of the skin on the lateral aspect of her left knee. She gave a history of using a laptop for prolonged hours. She did not feel any pain in her knee, however, noticed change in colour of the skin. Clinically, it appeared to be a first degree thermal burn. The burns sustained were due to close proximity of the extractor fan of the laptop over her left knee as she had been using the laptop. Heat lesions induced by the laptop are typically located on only one leg, normally on the left leg because the optical drives are located on the left side. ${ }^{5}$ The clinical examination otherwise of her left knee was normal. The skin around the lateral aspect on the knee had objective numbness which occurs due to injuring the infrapatellar branch of the saphenous nerve after midline approach to the knee joint for TKA. ${ }^{3}$

On examination, the scar and the skin on the lateral aspect of the scar looked mildly erythematous up to the inferior border of the patella (Figures 1 and 2). The patient was treated conservatively and advised to avoid using her laptop over her left knee for six weeks. When the patient was reviewed again after six weeks, the skin erythema had subsided. She was advised to avoid placing the laptop over her left knee as a precautionary measure.

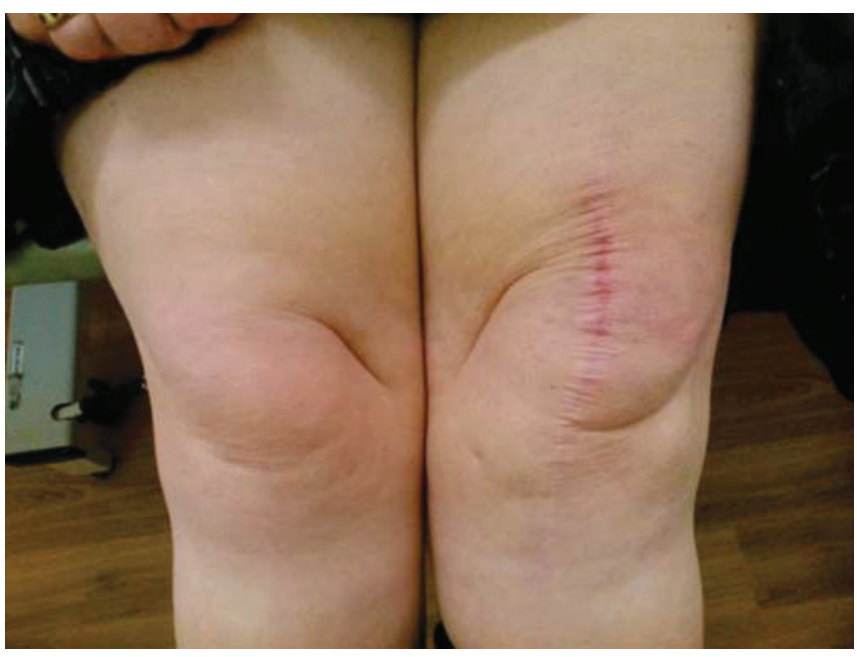

Figure 1: The scar and the skin on the lateral aspect of the scar looked mildly erythematous up to the inferior border of the patella

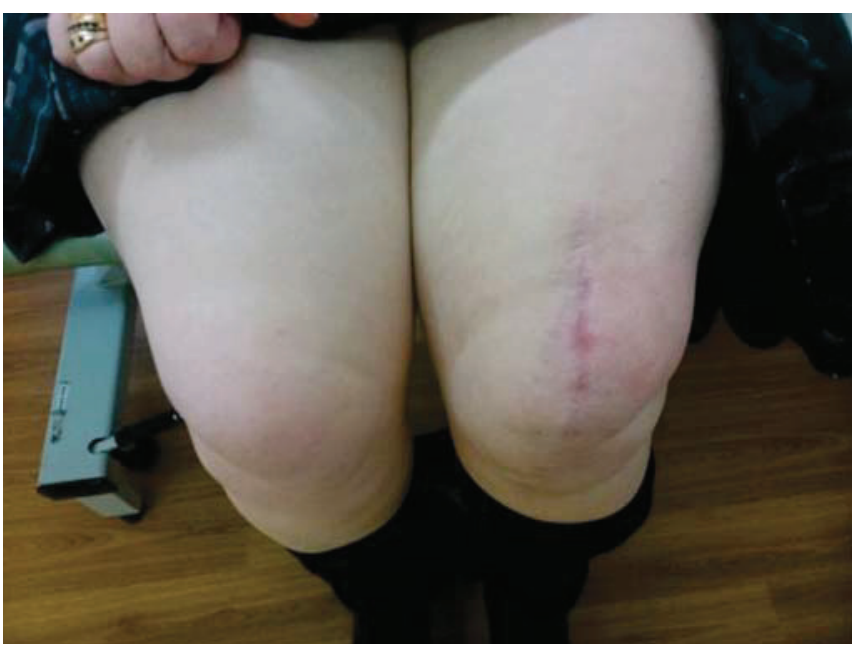

Figure 2: First degree burn of the knee corresponding to the placement of laptop over the thigh 


\section{DISCUSSION}

Hardware components in a laptop are in close proximity to each other with very little room for air movement which makes the laptop prone to overheating. ${ }^{7}$ In the modern era, there is an increased prevalence of laptop thermal burns. In most cases of laptop induced burns, patients are not aware of the heat resulting in delay in patient response. ${ }^{8}$ Exposure to sub maximal heat with infrared radiation is sufficient enough to cause a burn inducing dermal damage. ${ }^{9}$ We need to highlight the importance of such injuries when we are educating patients who are undergoing knee arthroplasty as this procedure invariably leaves a hypaesthesic patch of skin on the lateral aspect of the knee and makes them prone for the thermal injury. The numbness after total knee replacement is common. ${ }^{10}$ Mostly, such injuries can be managed conservatively but if severe thermal injuries happen then surgical intervention may be required in the form of debridement, skin grafting. ${ }^{3}$

\section{CONCLUSION}

This case report highlights the significant risk of using a laptop in individuals who have altered sensation after having total knee replacement. The management of such cases can be used to educate other arthroplasty surgeons to emphasise to patient about this possible risk associated with the prolonged use of laptops in their consultation and consent.

\section{CLINICAL MESSAGE}

Prevention is always better than cure and using a laptop on a table or desk can be the most effective way after total knee replacement.

\section{REFERENCES}

1. Nebu CJ, Adel Z, Khushroo HS. Thermal burns on lower limb resulting from laptop use: a case report and review of literature. Indian J Plast Surg 2014;47(3):441-443.

2. Palius K, Napoles P, Maguina P. Thigh burn associated with laptop computer use. J Burn Care Res 2008;29(5):842-844.

3. Patel SM, Leon-Villapalos J. Full thickness lower limb burn associated with laptop power adaptor. BMJ Case Rep [Online] 2011;Mar10. Available from: http://casereports.bmj.com/content/2011/ bcr.12.2010.3610.long (Date accessed 2017 May 12)

4. Black R, Green C, Sochart D. Postoperative numbness of the knee following total knee arthroplasty. Ann R Coll Surg Engl 2013;95(8):565568.

5. Andreas WA, Peter HI. Laptop computer-induced erythema ab igne in a child and review of the literature. Pediatrics 2010;126(5):1227-1230.

6. Tsang KS, Swan MC, Masood S. Full thickness thigh burn caused by a laptop computer: It's hotter than you think. Burns 2011;37(2):9-11.

7. Pinola $M$. The problem with overheating laptops. Available from: http://mobileoffice.about.com/od/ laptopstabletpcs/qt/dangers-of-laptop-overheating. htm. [Date accessed 2017 May 12].
8. Sharma G. Burn injury caused by laptop computers. Ann Med Health Sci Res. 2013;3(1):31-2.

9. Kligman LH. Intensification of ultraviolet-induced dermal damage by infrared radiation. Arch Dermatol Res. 1982;272(3):229-38.

10. Blackburn J, Wylde V, Greenwood R, Blom AW, Levy A. The effect of numbness on outcome from total knee replacement. Ann R Coll Surg Engl. 2017;99(5):385-389.

Source of support: Nil.

Conflict of interest: None declared.

Correspondence to: waqar.saadat@yahoo.co.uk

S. Muhammad Waqar Saadat, MBBS, MRCS, Mch (T\&O) Furness General Hospital, Dalton Lane LA14 4LF 